\title{
Experimental study on influence of aggregate gradation on properties of silica aerogel-glazed hollow beads composite insulation mortar
}

\author{
WANG Yiren ${ }^{1 *}$, JU Lian ${ }^{1}$, XU Jinmei ${ }^{1}$ and ZHANG Zhijun ${ }^{1}$ \\ ${ }^{1}$ Department of Architectural and environmental Engineering, Changzhou University Huaide College, Jingjiang, 214500, Jiangsu Province, \\ China
}

\begin{abstract}
Taking the defects of narrow range of particle gradation of glazed hollow beads and low mechanical strength of silica aerogel into consideration, silica aerogel and glazed hollow bead have been mixed for the composite aggregate of insulation mortar. Some measures, such as composite aggregate and particle gradation, were taken to optimize the properties of aggregate formulation, analyzing kinds of factors that influence on the properties of the mortar thoroughly, such as mechanical properties, thermal insulation properties and fire-resistance properties. Under the condition of $60 \mathrm{vol} \%$ aggregate content, it was found that compositing $35 \mathrm{vol} \%$ silica aerogel and $65 \mathrm{vol} \%$ glazed hollow beads as the composite aggregate was optimum for producing insulation mortar samples with suitable properties.
\end{abstract}

\section{Introduction}

Insulation mortar is a kind of building material for the surface of buildings, with cement as cementitious material, lightweight material as aggregate, and some modifiers and additives, which is formed by mixing and stirring. Because of good thermal insulation performance and workability, insulation mortar has been widely used in practical engineering ${ }^{[1]}$. As to the composition of thermal insulation mortar, thermal aggregate is one of the most important components of the mortar, occupying the most of volume. Glazed hollow beads, as the common thermal insulation lightweight aggregate, play an important role on the market, of which the spherical surface can improve the workability and reduce the dosage of water, and at the same time the internal porous structure can strength insulation performance and enhance particle strength ${ }^{[2]}$. However, the drawbacks that particle size is regular and the range of gradation is narrow cause the result in the increasing amount of cementitious materials, which makes dry density large and construction operation poor ${ }^{[3]}$. Silica aerogel, known as the lightest solid material and one of the best thermal insulation material, of which more than $90 \%$ volume is composed of tiny pores, possesses high porosity, high specific surface area, ultra-low density and extremely low thermal conductivity ${ }^{[4]}$. The ultra-low density and extremely low thermal conductivity of aerogel can respectively make up for the high dry density and thermal conductivity of glazed hollow beads mortar, while the particle strength of glazed hollow beads solve the problem of brittleness of aerogel. In addition, aerogel-glazed hollow beads composite aggregate form suitable particle gradation because of the particle size range of aerogel, which can reduce porosity of composite aggregate and increase compressive strength and flexural strength of mortar, and also can reduce the amount of cementitious materials needed for wrapping the lightweight aggregate, further cutting down the dry density of mortar ${ }^{[5]}$. Therefore, the aerogel-glass hollow beads composite aggregate mixing in a certain proportion can make optimum utilization and improve the comprehensive properties of mortar.

In this paper, the effect of different amount of silica aerogel instead of glass hollow beads on the physical and mechanical properties, thermal insulation properties and fire-resistance properties was studied by adding composite aggregate directly into mortar.

\section{Experimental}

\subsection{Raw materials}

The cement used in this study was oridinary Portland Cement 52.5 from Jiangsu Yangzi cement Ltd. SiO2 aerogel was produced by Guangdong Alison Ltd and glazed hollow beads were produced by Jiangsu Hua Weijia building material Ltd. Fly ash was from Changzhou Hutang thermal power plant, the density of which is $2500 \mathrm{~kg} / \mathrm{m} 3$.Latex powder and methyl cellulose ether(MC) from Shanghai Chen Qi Chemical Ltd were used to increase the workability. Modified polypropylene fiber from Shanghai Ying Jia Industrial Development Ltd was used to enhance strength of concrete. NRG-700 was selected as the superplasticizer (SP). 


\subsection{Mix proportion}

Mix proportion design of the silica aerogel-glazed hollow beads composite insulation mortar follows the Chinese standards GB/T20473-2006, and that of all insulation mortars are designed according to the volume method. The total volume of the aerogel and glazed hollow beads was fixed to $60 \%$, where the volume of aerogel was only changed. The details of bulk density and particle gradation of composite aggregate are listed in Table 1, and the details of mix proportions are listed in Table 2.

Table 1.Bulk density and particle gradation of composite aggregates.

\begin{tabular}{|c|c|c|c|c|c|c|c|c|}
\hline \multirow{3}{*}{ Sample } & \multirow{3}{*}{$\begin{array}{c}\text { Volume of } \\
\text { aerogel } / \mathrm{vol} \%\end{array}$} & \multicolumn{7}{|c|}{ Composite aggregates } \\
\hline & & \multirow{2}{*}{$\begin{array}{l}\text { Bulk density } \\
/\left(\mathrm{kg} / \mathrm{m}^{3}\right)\end{array}$} & \multicolumn{6}{|c|}{ Cumulative formation constant $/ \%$} \\
\hline & & & $4.75 \mathrm{~mm}$ & $2.36 \mathrm{~mm}$ & $1.18 \mathrm{~mm}$ & $0.60 \mathrm{~mm}$ & $0.30 \mathrm{~mm}$ & $<0.30 \mathrm{~mm}$ \\
\hline 1 & 0 & 122 & 0 & 0 & 0 & 50 & 82 & 100 \\
\hline 2 & 20 & 97 & 0 & 8 & 18 & 59 & 89 & 100 \\
\hline 3 & 30 & 83 & 0 & 12 & 23 & 61 & 93 & 100 \\
\hline 4 & 35 & 77 & 0 & 17 & 28 & 64 & 95 & 100 \\
\hline 5 & 40 & 72 & 0 & 19 & 33 & 71 & 96 & 100 \\
\hline 6 & 45 & 66 & 0 & 25 & 40 & 76 & 97 & 100 \\
\hline
\end{tabular}

Table 2.Mix proportion of silica aerogel-glazed hollow beads composite insulation mortar $(40 \mathrm{~mm} \times 40 \mathrm{~mm} \times 160 \mathrm{~mm})$.

\begin{tabular}{ccccccccccc}
\hline Sample & $\begin{array}{c}\text { Volume } \\
\text { of aerogel } \\
\text { /vol\% }\end{array}$ & $\begin{array}{c}\text { Aerogel } \\
(\mathrm{mL})\end{array}$ & $\begin{array}{c}\text { Glazed } \\
\text { hollow beads } \\
(\mathrm{mL})\end{array}$ & $\begin{array}{c}\text { Cement } \\
(\mathrm{g})\end{array}$ & $\begin{array}{c}\text { Fly ash } \\
(\mathrm{g})\end{array}$ & $\begin{array}{c}\text { SP } \\
(\mathrm{g})\end{array}$ & $\begin{array}{c}\text { Latex } \\
\text { powder } \\
(\mathrm{g})\end{array}$ & $\begin{array}{c}\text { Fiber } \\
(\mathrm{g})\end{array}$ & $\begin{array}{c}\text { MC } \\
(\mathrm{g})\end{array}$ & $\begin{array}{c}\text { Water } \\
(\mathrm{g})\end{array}$ \\
\hline 1 & 0 & 0 & 460.8 & 348.06 & 69.61 & 12.53 & 8.35 & 1.25 & 2.51 & 167.07 \\
2 & 20 & 92.2 & 368.6 & 348.06 & 69.61 & 12.53 & 8.35 & 1.25 & 2.51 & 167.07 \\
3 & 30 & 138.2 & 322.6 & 348.06 & 69.61 & 12.53 & 8.35 & 1.25 & 2.51 & 167.07 \\
4 & 35 & 161.3 & 299.5 & 348.06 & 69.61 & 12.53 & 8.35 & 1.25 & 2.51 & 167.07 \\
5 & 40 & 184.3 & 276.5 & 348.06 & 69.61 & 14.62 & 8.35 & 1.25 & 2.51 & 167.07 \\
6 & 45 & 207.4 & 253.4 & 348.06 & 69.61 & 18.80 & 8.35 & 1.25 & 2.51 & 187.95 \\
\hline
\end{tabular}

\subsection{Sample preparation}

The mortar were prepared according to a mixing method in GB/T20473-2006standard. First, all the dry powders of cement, fly ash, latex powder, fiber and MC were mixed together at low speed for $2 \mathrm{~min}$, then water was added to the mix, marking the start of hydration. The proper proportion of aerogel and glass beads composite aggregate was subsequently homogenized into the mortar mix manually to prevent excessive crushing. Consistency of $70 \sim 80 \mathrm{~mm}$ as the control index, some SP was added and mixed for 3 5min. When well homogenized, the mortar was cast into the standard $40 \times 40 \times 160 \mathrm{~mm}$ metal moulds, stored for 2 days before demoulding and cured in standard curing room (room temperature of $20 \pm 2^{\circ} \mathrm{C}$ and relative humidity of $>90 \%$ ) for 28 days before further analysis. The mortar block and the fracture surface are respectively shown in Figure 1(a), (b).

\subsection{Testing methods}

The compressive strength and flexural strength were tested according to the Chinese standards JGJ70-2009, and thermal conductivity referred to the Chinese standards GB/T 10294-2008. The concrete scaling time of the concrete with the insulation mortar sample coating was tested by high temperature furnace. The details were as follows: the high temperature furnace was used to simulate the condition of a fire caused by fibrous objects in general constructions. The heating rate was based on the temperature rising curve that could be represented by $T-T_{0}=345 \log _{10}(8 t+1)$, where T0 represented the initial temperature, meaning that temperature nearly reached $850^{\circ} \mathrm{C}$ within 30 minutes. The insulation mortar sample was coated on the surface of the concrete, and then the concrete was wrapped in rock wool, leaving only the coating surface exposed to the air, and subjected to the fire. And a camera, connected to a computer, in the high temperature furnace was used to observe the calcination of the concrete. The high temperature furnace is shown in Figure 1(c), (d). 

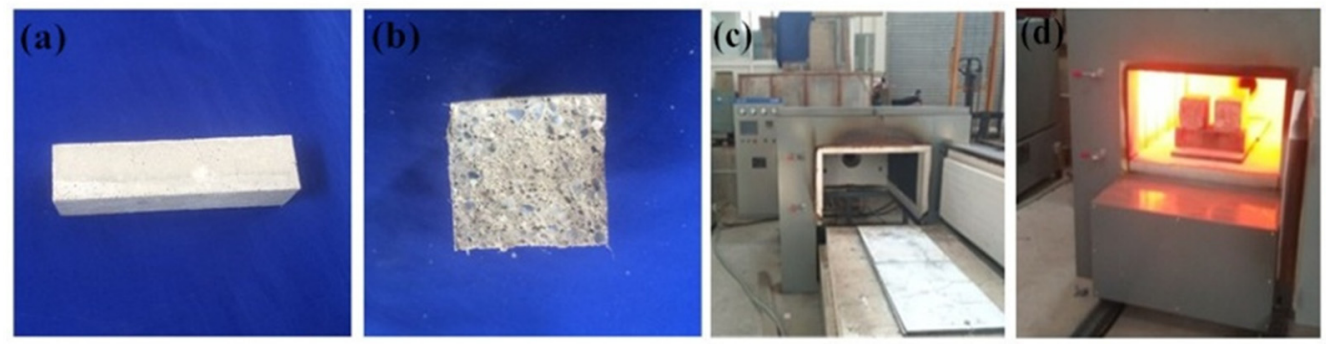

Figure 1.The mortar block and the high temperature furnace.

\section{Results and discussion}

\subsection{Mechanical strengths of insulation mortar samples}

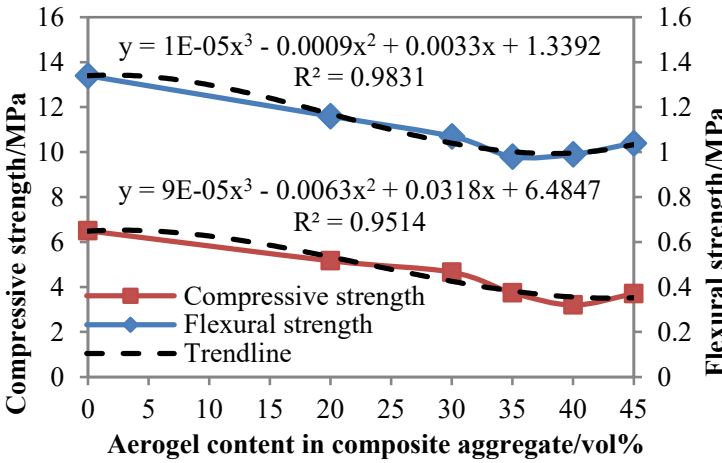

Figure 2.Compressive strength and flexural strength of different aerogel contents.

Following the similar trend, both flexural and compressive strengths dropped first and then slightly rose with the increasing aerogel content. The two trends could be represented by $y=1 E-05 x^{3}-0.0009 x^{2}+0.0033 x+1.3392$ and $y=9 E-05 x^{3}-0.0063 x^{2}+0.0318 x+6.4847$

respectively, to be detailed. With $35 \%$ and $40 \%$ aerogel content in the insulation mortar samples, it was possible to maintain a minimum flexural strength of $0.98 \mathrm{MPa}$ and compressive strength of $3.2 \mathrm{MPa}$. When continuing on the aerogel content to $45 \%$, the flexural strength and compressive strength were slightly improved to $1.04 \mathrm{MPa}$ and $3.7 \mathrm{MPa}$.

The initial rapid drop in strengths of the insulation mortar samples can be attributed to a decrease inadhesion between the aggregate particles and insulation mortar. For the high porosity and specific surface area of aerogel, the superficial area of the aggregates in the system increases with the increasing aerogel content $t^{[6]}$. As a result, cementitious materials in the system can't fill the voids between the aggregate and wrap the aggregate. However, the voidage of composite aggregate reduces when the aerogel content increases to a certain extent for the reason that aerogel particles and glass hollow beads filling voids of each other in the system more thoroughly, which accounts for the rise in strength in later period.
The aggregate used in the test is a composite of glass hollow beads and aerogel, the volume of which was set to $60 \%$ of the total volume of mortar. Figure 2 presents the compressive and flexural strengths of the insulation mortar samples as a function of aerogel content.

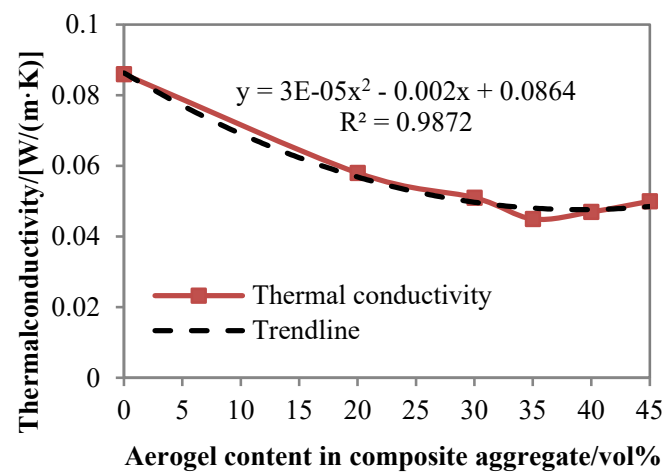

Figure 3.Thermal conductivity of different aerogel contents.

\subsection{Thermal conductivity of insulation mortar samples}

Figure 3 exhibits the thermal conductivity of the insulation mortar samples as a function of aerogel content.

As can be seen from Figure 3, the overall trend can be fitted to a polynomial curve with a good fit of $R^{2}>0.98$.An increase in aerogel content decreased the thermal conductivity of the insulation mortar samples from an initial $0.086 \mathrm{~W} /(\mathrm{m} \cdot \mathrm{K})$ to $0.045 \mathrm{~W} /(\mathrm{m} \cdot \mathrm{K})$ when $35 \%$ aerogel was present. In contrast to the trend line of $y=3 E-05 x^{2}-0.002 x+0.0864, R^{2}=0.9872$, the thermal conductivity dropped rapidly especially when aerogel content ranged from $30 \% \sim 35 \%$, which showed that $30 \% \sim 35 \%$ aerogel could effectively improve the thermal insulation properties of mortar. This is because more than $90 \%$ of the volume of aerogel is make up of tiny nano pores, the size of which is less than molecular average free path of air in the pores, resulting in the sharp drop in the thermal conductivity ${ }^{[7,8]}$. However, the thermal conductivity of the insulation mortar samples containing $45 \%$ aerogel displayed an increased thermal conductivity of $0.05 \mathrm{~W} /(\mathrm{m} \cdot \mathrm{K})$. This phenomenon may be partially explained by the fact that some aerogel particles are crushed during mixing, thus losing their insulating 
properties partially.

\subsection{Spalling time of concrete with insulation mortar samples coating under fire}

For this part, the spalling time of concrete under fire was used to describe the fire-resistance property of mortar, which begins with the calcination of the concrete with mortar coating and ends with the concrete scaling. The insulation mortar was coated on the surface of C60 concrete $(150 \times 150 \times 150 \mathrm{~mm})$ and then put into a high-
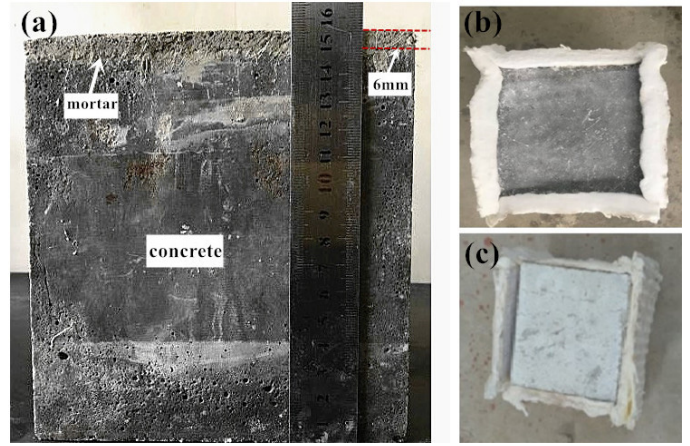

Figure 4. The concrete block with the mortar sample coating.

As is known from Figure 5, the spalling time expanded gradually with the increase of aerogel content, reflecting the excellent thermal insulation properties of silica aerogel. Furthermore, this trend could be fitted to a polynomial curve by $y=-0.025 x^{2}+2.277 x+126.6$, $R^{2}=0.927$ Compared with the spalling time of concrete without mortar coating, the time required for spalling of concrete coated with insulation mortar appeared to be longer, which indicated that coating insulation mortar on the surface contributed to extending the concrete spalling time. The overall increasing spalling time signified an obvious improvement on the adiabatic effect of insulation mortar. When $35 \%$ aerogel was present in composite aggregate, the longest time of $168 \mathrm{~min}$ required for concrete scaling was detected. It may be attributed by the increase of aerogel content that greatly inhibits the heat conduction efficiency. At a higher aerogel content of $35 \% \sim 45 \%$, a slight drop by $7 \%$ in spalling time was detected (171 versus 183 respectively). The phenomenon can be explained that when the aerogel content continuously gets increasing, the composite aggregate gets looser and the connected pores grow larger between the dense cement base and the composite aggregate $^{[9]}$. The heat transfers through the convection and radiation in the pores and as a result, the fire-resisting property of the mortar declines to a certain degree.

\section{Conclusions}

The composite aggregate formulation was utilized to optimize the properties of insulation mortar based on aerogel-glass hollow beads incorporation. It was observed that increasing aerogel content resulted in a drastic drop in temperature furnace, with composite aggregate taking $60 \%$ of the mortar and aerogel content respectively taking $0 \%$, $20 \%, 30 \%, 35 \%, 40 \%$ and $45 \%$ of the composite aggregate In addition, a binder was used to obtain better interfacial bonding force between mortar and concrete, and the thickness of the coating was $6 \mathrm{~mm}$, as is shown in Figure 4(a). The appearances of concrete with mortar coating before and after the fire-resistance test are shown in Figure 4(b) and Figure 4(c), respectively. Figure 5 exhibits spalling time of concrete coated with mortar samples as a function of aerogel content.

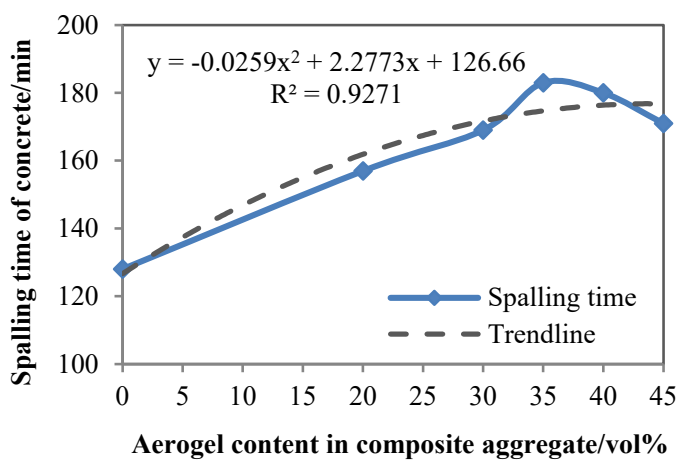

Figure 5. Spalling time of concrete coated with mortar of different aerogel contents.

the mechanical strength of the insulation mortar samples, which owed to the high porosity and specific surface area of aerogel. At an aerogel content of $35 \mathrm{vol} \%$ where a minimum flexural strength of $0.98 \mathrm{MPa}$ was maintained, a minimum thermal conductivity value of $0.045 \mathrm{~W} /(\mathrm{m} \cdot \mathrm{K})$ along with a maximum concrete scaling time of $183 \mathrm{~min}$ was also obtained at the same time. Thus, the optimum composite aggregate of the insulation mortar should be $35 \mathrm{vol} \%$ aerogel and $65 \mathrm{vol} \%$ glass hollow beads. The ultimate goal of the construction material exhibiting both satisfactory thermal and mechanical properties will be achieved.

\section{Acknowledgements}

The work described in this paper was fully supported by The Natural Science Foundation of China (No.51678080, No.51678081).

\section{References}

1. Wang W.C, Li Z.W. (2013) Progress on Energysaving Technology on External Wall. Science \& Technology Review, Vol.13, pp.76-79.

2. Xiu H.G, Zhu L, Guo Q.Z. (2011) The Application of Glazed Hollow Beads in Thermal Insulation Structure of Gallery and its Energy Conservation Effect. Advanced Materials Research, Vol.250-253, pp.895900 .

3. Li W.L, Wang J, Geng G.Q. (2014) Optimizing the Design of New Composite Insulation Mortar Recipe. Materials Review, Vol.S2, pp.356-359.

4. Wang F, Liu Z.H, Deng Z.P, et al.(2016)Effect on the 
performance of mortar using different volume content of $\mathrm{SiO}_{2}$ aerogel. Journal of Functional Materials, Vol.04, pp.64-69.

5. Guo J.T. (2011) Study on silica aerogel/glazed hollow beads composite thermal insulating mortar. Chang'an University, Xi'an.

6. Zeng L, Huang S.W, Hu X, et al. (2008) Influence of aggregate grading on properties of expanded perlitevitrified microsphere thermal insulation mortar. New Building Materials, Vol.12, pp.56-59.

7. Ni W, Xu L, Liu F.M. (2007) Experimental study on expanded perlite/glass bead composites. New Building Materials, Vol.03, pp.42-44.

8. Bulent Y, Paki T. (2009) Thermal insulation enhancement in concretes by adding waste PET and rubber Pieces. Construction and Building Materials, Vol.23, pp.1878-1882.

9. Serina Ng, Jelle B.P, Sandberg L.I.C. (2015) Experimental investigations of aerogel-incorporated ultra-high performance concrete. Construction and Building Materials, Vol.77, pp.307-316. 